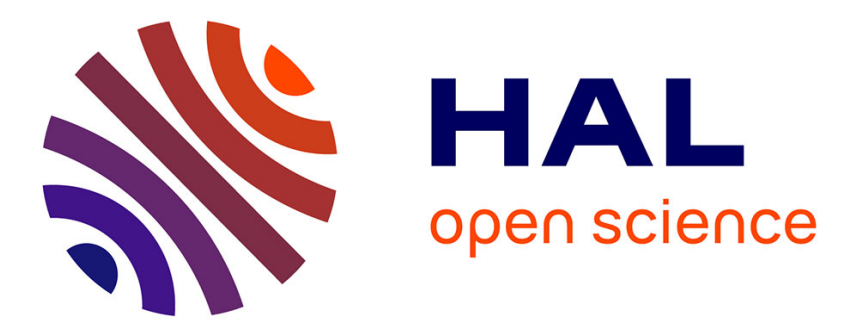

\title{
Ecological constraints on the first prehistoric farmers in Europe
}

William E. Banks, Nicolas Antunes, Francesco d'Errico, Solange Rigaud

\section{To cite this version:}

William E. Banks, Nicolas Antunes, Francesco d'Errico, Solange Rigaud. Ecological constraints on the first prehistoric farmers in Europe. Journal of Archaeological Science, 2013, 40 (6), pp.2746-2753. 10.1016/j.jas.2013.02.013 . hal-01180654

\section{HAL Id: hal-01180654 https://hal.science/hal-01180654}

Submitted on 24 Nov 2020

HAL is a multi-disciplinary open access archive for the deposit and dissemination of scientific research documents, whether they are published or not. The documents may come from teaching and research institutions in France or abroad, or from public or private research centers.
L'archive ouverte pluridisciplinaire HAL, est destinée au dépôt et à la diffusion de documents scientifiques de niveau recherche, publiés ou non, émanant des établissements d'enseignement et de recherche français ou étrangers, des laboratoires publics ou privés. 
Archaeological Science

Elsevier Editorial System(tm) for Journal of

Manuscript Draft

Manuscript Number: JASC13-46R1

Title: Ecological constraints on the first prehistoric farmers in Europe

Article Type: Full Length Article

Keywords: Eco-Cultural Niche Modeling; European Early Neolithic;

Linearbandkeramik; Impressed Ware Culture; Cardial Ware Culture

Corresponding Author: Dr. William E. Banks, Ph.D.

Corresponding Author's Institution: CNRS

First Author: William E. Banks, Ph.D.

Order of Authors: William E. Banks, Ph.D.; Nicolas Antunes, M.A.; Solange Rigaud, Ph.D.; Francesco d'Errico, Ph.D.

Manuscript Region of Origin: FRANCE

Abstract: The Neolithic Revolution, which witnessed the transformation of hunter-gatherer groups into farming communities, is traditionally viewed as the event that allowed human groups to create systems of production that, in the long run, led to present-day societies. Despite the large corpus of research focused on the mechanisms and outcomes of the Neolithic transition, relatively little effort has been devoted to evaluating whether particular production-oriented adaptations could be integrated into a broad range of ecological conditions, and if specific cultural traditions differed ecologically. In order to investigate whether the differences between the adaptations and geographic distributions of three major Early Neolithic archaeological cultures are related to the exploitation of different suites of environmental conditions, we apply genetic algorithm and maximum entropy ecological niche modeling techniques to reconstruct and compare the ecological niches within which three principal Neolithic cultures (Impressed Ware, Cardial Ware, and Linearbandkeramik) spread across Europe between ca. 8000-7000 cal yr BP. Results show that these cultures occupied mutually exclusive suites of environmental conditions and, thus, were adapted to distinct and essentially non-overlapping ecological niches. We argue that the historical processes behind the Neolithization of Europe were influenced by environmental factors predisposing occupation of regions most suited to specific cultural adaptations. 


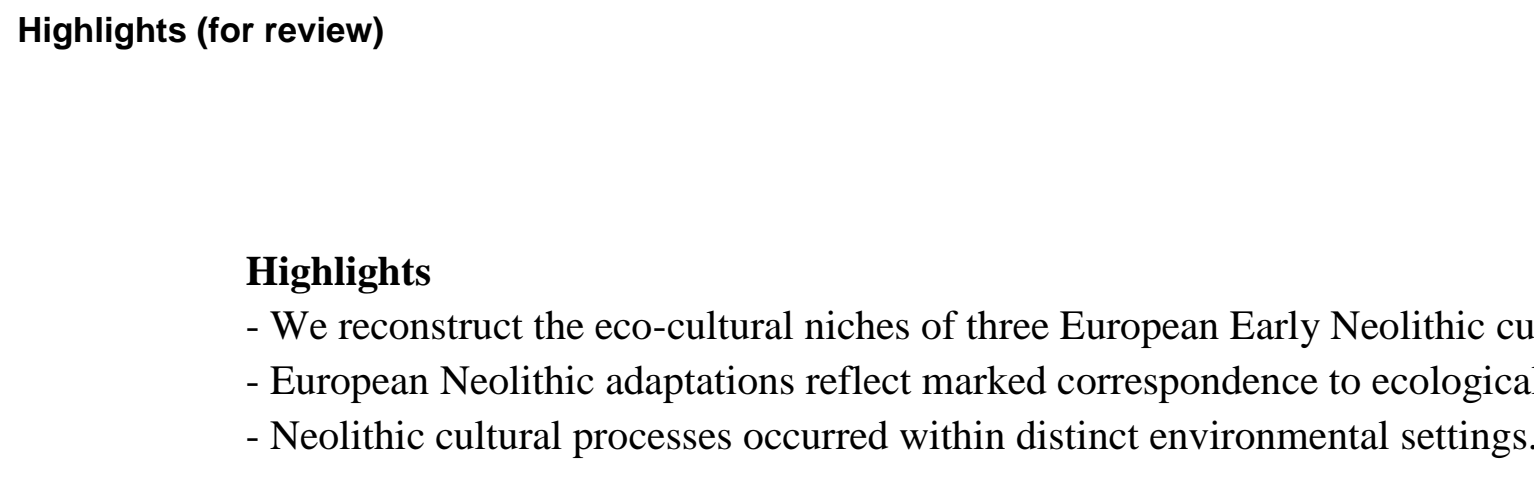

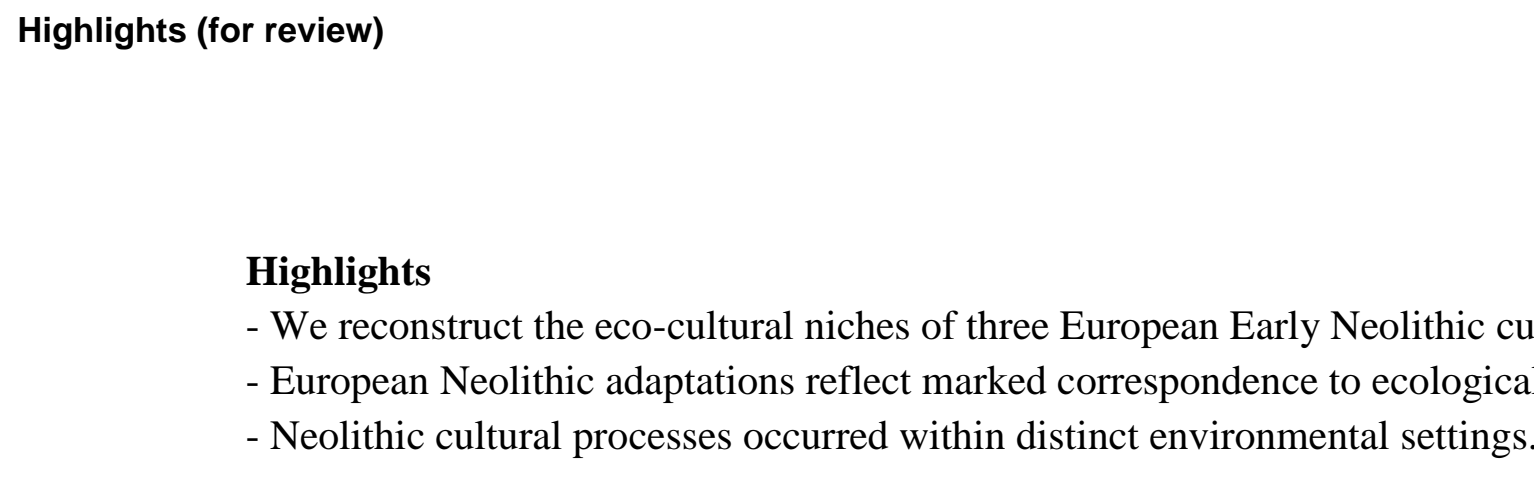

Highlights (for review)
\[ \begin{array}{l}\text { Highlights } \\ \text { - We reconstruct the eco-cultural niches of three European Early Neolithic cultures. } \\ \text { - European Neolithic adaptations reflect marked correspondence to ecological paran } \\ \text { - Neolithic cultural processes occurred within distinct environmental settings. }\end{array} \]

Highlights (for review)
\[ \begin{array}{l}\text { Highlights } \\ \text { - We reconstruct the eco-cultural niches of three European Early Neolithic cultures. } \\ \text { - European Neolithic adaptations reflect marked correspondence to ecological parameters. } \\ \text { - Neolithic cultural processes occurred within distinct environmental settings. }\end{array} \]

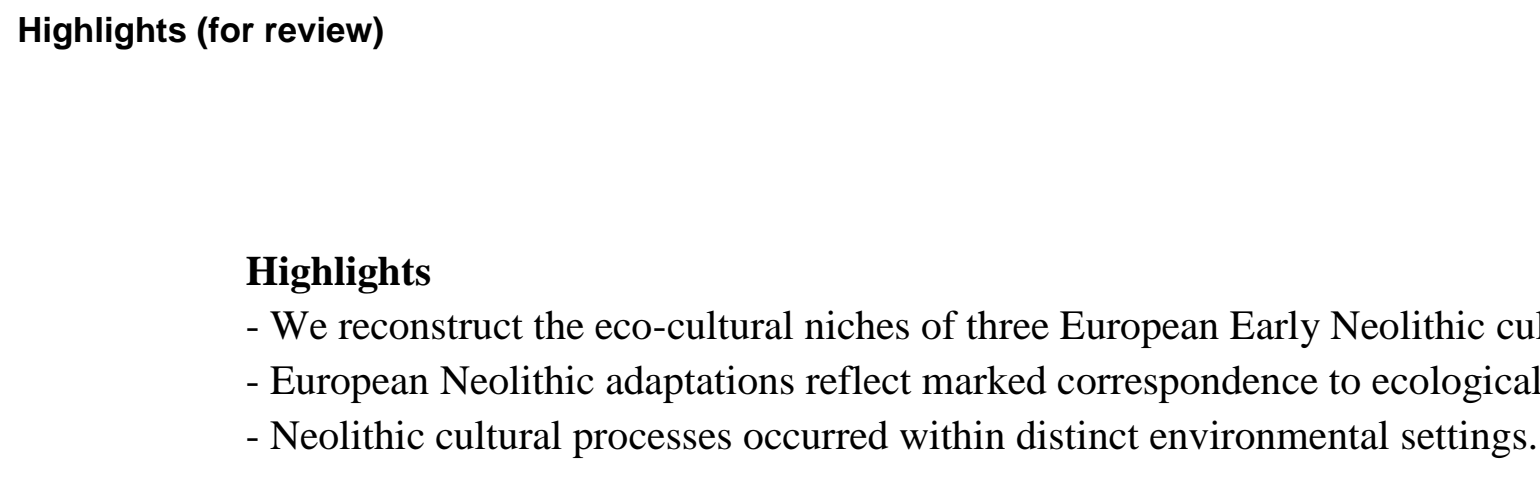

\author{
(
}


February 14, 2013

\section{Dear Dr. Klein,}

We have read with attention the comments provided by the two referees and have attempted to address all of their concerns with an extensive revision of the originally submitted manuscript. There are a couple of instances, though, for which we disagree with their comments and think that changes along such lines are either unwarranted or beyond the scope of this paper. Below, we detail our responses (most of which are associated with revisions to the text) to each specific reviewer comment (reviewer comments are in italics).

Cordially,

Will Banks and co-authors

Reviewer \#1:

1. It has to be made clear why one should accept archaeological entities, especially "Cardial" and "Impressa", as distinct cultural units. I think that the authors should provide a more detailed discussion of what is an archaeological culture and how it is defined... There has to be more discussion right at the start of the paper about these cultures and what was the rationale to look at these specific cultures and not also the SKC (see below).

In the revised version of the manuscript, we now define specifically what we mean by archaeological culture, how this concept is tied to our use of the term adaptive system, and how such a concept is integrated into an eco-cultural niche modeling approach (pg. 5). Furthermore, we have inserted text that makes it clear that we are interested in broadly defined archaeological cultural entities and not smaller-scale, regional variants that existed within them. In conjunction with those revisions, we have added text that makes it clear that we are interested in these three principal cultural complexes because they are the ones associated with the expansion of the Neolithic adaptation across Europe. We think that the additions we have made here are sufficient to indicate our standpoint to the reader.

2.Are climatic envelopes a true representation of ecological niches? It may be the case, but this needs to be better explained to the readers.

In the second paragraph of the revised introduction, we now clearly define the concept of ecological niche that we use in this study, and how with this "Grinnellian" niche concept, the climatic and geographic variables that we employ can be used to reconstruct/approximate an ecological niche. Because it was a source of confusion in the original text, we have eliminated the term climatic envelope throughout the revised text and instead only use ecological niche since there is now no ambiguity as to what we mean by this term.

3. On page 8 you indicate that the LMDZ4 palaeoclimate simulation has a horizontal resolution of 70-90 km. If this is the case, does it not mean that your overall resolution in terms of climatic envelope is rather crude, as we are dealing with for example, the Italian Peninsula, which is a rather narrow? 
In response to this comment, we have added a statement that this resolution is appropriate for the geographic scale of our analysis (pg. 10). In fact, since our geographic focus is the European continent, a grid cell resolution of ca. $80 \mathrm{~km}$ is not really all that coarse. Unfortunately, there is not much more that we can do in response to this criticism in that we are working with the best data that we have available to us.

4. On page 5 the authors do not explain why the skip the Starcevo-Koros-Cris and Karanovo complexes of SE Europe and move to look at LBK and Cardial/Impressa. Cardlal/Impressed is contemporaneous with SKC rather than LBK as LBK is mostly falling between 5500-4800 cal BC and hence starting more or less after the end of the main spread of the Mediterranean Impressed Ware and Cardial cultures. In my opinion, leaving the SKC/Karanovo out of the model, provides a somewhat odd picture as $L B K$ was subsequent to $S K C$.

In response to this comment, we have introduced a number of changes to the text that better explain our rationale, and hence justify the exclusion of the SKC complex. First, we have clarified that we are interested in examining the cultural adaptations associated with the major Neolithic expansions across Europe (pg. 5), rather than the first appearance of the agricultural adaptation in Europe which is the case for SKC complex. We now explicitly state that the LBK is thought to have emerged out of the SKC and it is the LBK that spread through Central and northwestern Europe.

It is clear that the time ranges we provided for these archaeological cultures in the original text were overly broad and thus a source of confusion. In light of this shortcoming, we have refined these time ranges to better reflect the available data, and thus our revised text states that the individual expansions of these cultures are largely contemporaneous when ages from diagnostic materials are considered. To further clarify our chronological age ranges we have added a statement that when $14 \mathrm{C}$ ages from diagnostic materials are examined, the eastern Impressa/Cardial are contemporaneous with the early LBK (pg. 6). It is possible that the reviewer is referring to older radiocarbon ages obtained on bulk charcoal samples that suggest that the Impressed/Cardial complexes are much older than the LBK. We think that our revisions serve to clarify this issue and have eliminated what was clearly a source of confusion.

5. On page 15 you state that "This study's results lead us to conclude that environmental factors influenced the cultural processes that characterize the Neolithization of Europe". I do not think that the results of this study support this claim. What the simulations do is to find the best fit model for the given occurrence data (archaeological sites). As good as the fit may be, it does not necessarily indicate that the people of the cultures at hand were particularly influenced by environmental factors in their (pre)historical decision making of where to settle.... If we start from the Null hypothesis that these two waves ... colonized distinctly different European environments (Mediterranean vs. continental), then the fact that the eco-niche modeling reaffirms this, is not surprising. Of course one can also reverse this and claim that the Null hypothesis should be preferences for different eco-niches, but the point is that modeling farmers which disperse in a logistic fashion across the continent, is not the same thing as modeling huntergatherers with very large territories/networks. I therefore think that more has to be done in order to convince the readers that these aspects have been taken into consideration. 
We disagree with this comment, but since it was made it shows a need for things to be clarified in the text. To this end, we now state in the Discussion and Conclusion section (pg. 15) that it is in fact this absence of overlap that is most important and which is completely unexpected even if one assumes from the beginning that these two broad cultural expansions were associated with different environments from their outset. Our revised text states that it is this lack of overlap that signals the presence of a strong culture-environment relationship that can be used to infer the important role of environmental factors in the Neolithization process. Furthermore, such a standpoint is now unambiguous in light of the revisions that we have made (in response to another comment made below by this same reviewer) to our hypothetical expectations between archaeological distributions, culture-environment relationships, and the geographic expressions of predicted eco-cultural niches (pg. 7).

6. Furthermore. unlike the eco-niche modeling of pre-Neolithic cultures (e.g. Banks et al JHE, 2013), Neolithic settlers have brought with them their subsistence package. It is true that they had to make specific decisions in regard to what environment will be suitable for rearing livestock, and harvesting specific crops, but these were to a large extent depending on microregional aspects which are not covered by this modeling approach (soil type, geology, proximity to water sources, sunlight, etc). I think that the eco-niche modeling is not applicable to the Neolithic as such. In order to apply it, one needs to take into consideration a range of additional factors, mainly the economy in terms of crops, and livestock.

We disagree with the referee on this point and think that the revisions we have made in response to other comments sufficiently address this criticism. We make it very clear in the revised manuscript that we are interested in looking at potential differences in the cultureenvironment relationships between these broadly defined Early Neolithic archaeological cultures, and that we are not concerned with minor, more regional, cultural subdivisions that might be defined within these broader archaeological cultural units (pg. 5). What we have done is show that on a continental scale, there are climatic, and to a lesser degree geographic, variables that serve to significantly differentiate the ecological conditions exploited by the principal European Neolithic cultures. Therefore, we would argue that for those who think that smaller-scale variables are more influential and that regional cultural variability is more important and should be the focus of study, the ball is now in their court to demonstrate that this is the case.

With respect to his/her comment on environmental parameters, we would argue that sunlight and proximity to water are represented by some of the variables (e.g., aspect and topographic index, respectively) that we incorporated into our generation of niche predictions. Secondly, we already stated that it would be ideal to include data on soil type and geology, and that at present it is difficult to ensure that the collection of such data would be geographically consistent across the European continent.

\section{More specific comments:}

Abstract needs to be more informative. It does not provide specific details about the cultures, the methods applied and results.

We have added statements to the abstract that point out how this study is focused on a subject that has received relatively little attention in the Neolithic literature, that specifically identify the methods used, and the archaeological cultures of interest. 
Page 3 introduction "progressive reliance (Rindos 1984) : should be changed to something like "human-plant coevolutionary relations"? I also think that the list should include Bocquet-Appel, when discussing demography, and Hodder and their theoretical stands as well as Redding, and Hayden? Alternatively the readers can be refereed to some of the main books and/or review papers.

We have changed the term describing Rindos' causal explanation and we have added an appropriate reference to the work carried out by Bocquet-Appel with respect to demography. Since it is beyond the scope and interest of this paper to delve into the extensive debate surrounding the multitude of potential causes behind the Neolithic revolution, we have chosen the alternative option suggested by the reviewer and cite work that covers this topic in detail (pg. 3).

Page 3 bottom, this is important but a bit hard to follow. The authors are saying that ecology is a major factor that we need to examine in the context of the spread of specific Neolithic "cultures" but then they mention that they will examine the distribution of these cultures in the context of climatic envelopes (which is by itself a term that you need to explain earlier on) and that these will inform us about different ecological niches.

As detailed in our response to this reviewer's point \#2, in the revised manuscript we explain how with respect to the Grinnellian concept of niche, one can use a combination of abiotic variables to approximate a past ecological niche. Additionally, throughout the manuscript, we have eliminated the term climatic envelope since it was a source of confusion and is no longer pertinent in light of our revisions that clarify the definition of ecological niche that is used.

Pp 5-6: It is also unclear as to what the authors refer to when they discuss environmental conditions. In one part they mention that eco-cultural niche modelling is applied in order to assess the extent to which Neolithic farming economies were constrained by environmental constraints. They also state below that they can assess whether cultural processes that occurred during the development of these cultures involved distinct environments or were driven by historical contingencies. They assume that in the case of the former, there will be on interpredictivity between ecological niches associated with different cultures and that each predicted ecological niche will correspond closely to its actual geographic distribution. If on the other hand the geographic distributions overlap then it is assumed to imply that there is no relationship between cultural and ecological parameters. As discussed above, this has to be better explained to the readers.

In light of this comment, we have revised this discussion so that it is better explained. We have done this by adding greater detail to the explanations of these null expectations and have made the potential expressions of differing degrees of the link between adaptation and ecology more explicit (pg. 7).

In sum, I think that the paper in many respect is stating the obvious which is that the spread cultures with a known geographic range which did not overlap correspond to some extent to specific environmental preferences. Given the fact that the environmental conditions in central Europe differed from those in coastal Mediterranean Europe it is of no surprise that the ecological modelling results reaffirms it. 
Again, in response to this viewpoint (to which we have already responded above and for which we detail the numerous related revisions), we have added statements that detail that it is the complete lack of overlap between the two niches that is unexpected and important. It is this lack of overlap that points to the influential role of environmental factors behind the cultural processes associated with the expansions of these two agricultural adaptations.

As these Neolithic cultures brought with them a Neolithic package which included a set of crops and particular livestock it is difficult to see how these cultural units can be assessed in the same manner as palaeo hunter-gatherers. The latter had to rely exclusively on available "wild" resources. Since the two major cultural units had different economic preferences, mainly herding sheep/goats vs. herding cattle, they will end up occupying different environments.

In light of this comment, we have included a statement in the revised text that whether one is examining h-g or farming populations, one can assume that the same general relationships between culture, ecology, and geographic distributions will apply to both types of adaptation. However, we disagree with this reviewer's comment and have clarified in our revisions that even if different economic preferences will end up occupying different environments, one would not expect these environments to be largely mutually exclusive.

I think that you should make a stronger case, perhaps by modeling an additional culture (SKC for example) and/or taking into consideration differences in subsistence between these entities. It may be the case that the results will provide an even stronger case for the fact that these cultures indeed depended on a specific niches, but if so, it will be good to know what characterized these, and how these models fit (if they do) with subsistence data (faunal and botanical data which is available online and from the literature).

We have inserted brief statements in a number of locations that make it clear that our focus is on the Neolithic expansion across Europe and not its initial appearance in the extreme southeastern portions of the continent. Thus, since our focus is on the expansion of Neolithic adaptations across Europe, we do not think it is necessary to conduct modeling work on the earliest Neolithic presence in southeastern Europe that precedes this expansion.

Another issue which should be taken into consideration is chronology. It is not clear why the authors did not apply the same Bayesian approach that they used in their recent 2013 JHE paper to radiocarbon dates. This will provide a good indication regarding the timing and tempo of their expansion which is a major parameter that is not discussed in this work.

We think that with some text additions, it is now clear in the revised manuscript that we are interested in comparing the ecological niches occupied by the principal Neolithic cultures after they had expanded across Europe. We refer to their roughly contemporaneous age ranges and have added references and examples that demonstrate this broad contemporaneity. The ecological dynamics within the Neolithic expansion events are not the focus of this paper, and thus there is no need to perform a Bayesian analysis of all available radiocarbon ages, which would serve to differentiate the timing of specific events and movements within these broad expansion events. Therefore, it is our opinion that a Bayesian analysis of $14 \mathrm{C}$ ages would be superfluous to our objective and would not add any relevant information to the study. Furthermore, once a Bayesian 
age model were run and specific time intervals of interest identified, one would need multiple paleoclimatic simulations for those specific climatic episodes or intervals during the early Holocene in order to reconstruct and compare eco-cultural niche predictions through time, and such paleoclimatic simulations do not exist.

Reviewer \#2: The statement (page 3) that:

Along with these changes, it is recognized that a switch to agriculture resulted in, at least during initial phases, more intense labor, a less diversified diet, increased morbidity, decreased life expectancy, precarious household-based production systems, and increased intra- and intergroup conflict is not supported by a lot of recent bioanthropological analysis of Neolithic skeletons - see, for instance, many papers in R. Pinhasi and J. Stock (eds), Human Bioarchaeology at the Transition to Agriculture. Chichester: Wiley-Blackwell. It might work for later eras, but that is beside the point. Early Neolithic populations probably had quite healthy lives compared to many of their descendants.

In our revisions (pg. 3), we state that while the occurrence of these drawback is generally recognized, there are a number of studies that present evidence to the contrary and we cite three recent and appropriate studies from the Pinhasi and Stock edited volume.

On page 5 it is stated that LBK dispersal began 8000 BP, but most sources I think prefer 7400 BP (5400 BC). I think also that the difference between Impresso and Cardial should be stated more clearly - this will not be obvious to non-specialists. The LBK is more clearly defined.

We have changed the beginning age for the early LBK to 7700 cal BP based on the calibrated age from a LBK burial in Central Europe (site of Schwanfeld), which is ca. 7600 cal BP. We have also added more descriptive details on what principal ceramic traits are used to define the LBK, Impressed Ware and Cardial cultural traditions (pg. 6). With respect to domesticated cultigens, we already provide a detailed description of the differences between these cultures in the Discussion section of the manuscript.

Page 6 states

However, eco-cultural niche modeling methods have never been applied to the European Early Neolithic in order to quantitatively assess the degree to which these farming economies were constrained by environmental constraints.

But I think that Coward, F. et al. 2008. The spread of Neolithic plant economies from the Near East to northwest Europe: a phylogenetic analysis. JAS 35:42-56. made some progress in this regard, and this paper should be quoted. This is also relevant for the discussion of crops on pages 13-14.

Coward et al. (2008) point out that regional changes in plant packages cannot be explained solely by ecology/environment, so we have added a statement to that effect and cited them in the part of the discussion that deals with cultural processes (pg. 17). We think this revision should be sufficient since one of the major aims of Coward et al.'s analysis was to determine whether these packages were spread via demic or cultural diffusion. Therefore, their work is not entirely pertinent to our statement that there is a strong need to quantify the relationship between farming 
economies and environmental factors - such a statement is only tangentially related to Coward et al.'s study of phylogenetic variability of cultigen packages.

One might ask if the Alps themselves played a major role in the LBK-Cardial differentiation. The Alps must also have played the major causal role in creating the environmental differences that are noted. Some have suggested that these two cultures actually mingled in France, around the western edge of the Alps.

The citation concerning contact zones that we included in the original manuscript was fairly limited in scope, so we have added a citation for Bocquet-Appel et al.'s work (2009) in which the subject of these limited contact zones is dealt with in detail. 
Ecological constraints on the first prehistoric farmers in Europe

William E. Banks ${ }^{1,2}$, , Nicolas Antunes ${ }^{1}$, Solange Rigaud ${ }^{1}$, Francesco d'Errico ${ }^{1,3}$

1 - CNRS, UMR 5199-PACEA, Université Bordeaux 1, Bâtiment B18, Avenue des Facultés, 33405 Talence, France

2 - Biodiversity Institute, University of Kansas, 1345 Jayhawk Blvd, Dyche Hall, Lawrence, KS 66045-7562, USA

3 - Department of Archaeology, History, Cultural Studies and Religion, University of Bergen, Øysteinsgate 3, 5007 Bergen, Norway

* - corresponding author: w.banks@ @acea.u-bordeaux 1.fr

\section{Highlights}

- We reconstruct the eco-cultural niches of three European Early Neolithic cultures.

- European Neolithic adaptations reflect marked correspondence to ecological parameters.

- Neolithic cultural processes occurred within distinct environmental settings.

\section{Keywords}

Eco-Cultural Niche Modeling

European Early Neolithic

Linearbandkeramik

Cardial Ware Culture

Impressed Ware Culture 


\section{ABSTRACT}

The Neolithic Revolution, which witnessed the transformation of hunter-gatherer groups into farming communities, is traditionally viewed as the event that allowed human groups to create systems of production that, in the long run, led to present-day societies. Despite the large corpus of research focused on the mechanisms and outcomes of the Neolithic transition, relatively little effort has been devoted to evaluating whether particular production-oriented adaptations could be integrated into a broad range of ecological conditions, and if specific cultural traditions differed ecologically. In order to investigate whether the differences between the adaptations and geographic distributions of three major Early Neolithic archaeological cultures are related to the exploitation of different suites of environmental conditions, we apply genetic algorithm and maximum entropy ecological niche modeling techniques to reconstruct and compare the ecological niches within which three principal Neolithic cultures (Impressed Ware, Cardial Ware, and Linearbandkeramik) spread across Europe between ca. 8000-7000 cal yr BP. Results show that these cultures occupied mutually exclusive suites of environmental conditions and, thus, were adapted to distinct and essentially non-overlapping ecological niches. We argue that the historical processes behind the Neolithization of Europe were influenced by environmental factors predisposing occupation of regions most suited to specific cultural adaptations. 


\section{Introduction}

The Neolithic Revolution represents the process by which human groups switched from hunting and gathering wild resources to a reliance on systems of food production based on domesticated plants and animals (Barker, 2006). The reasons for this transformation, which occurred independently and at different times in various regions of the world, have been debated for decades and are not fully understood (Bellwood, 2005; Barker, 2006). Proposed causes include climate change (Richerson et al., 2001; Weninger et al., 2006; Gronenborn, 2009; Rowley-Conwy and Layton, 2011), human-plant co-evolution (Rindos, 1984), demography (Bocquet-Appel, 2002; Bowles, 2011), social competition and inequality (Mithen, 2007), or a combination of these (see Ammerman and Biagi, 2003 as well as Bocquet-Apple and Bar-Yosef, 2008 for detailed reviews of the topic). Despite considerable debate concerning proposed causes and mechanisms, consensus exists that this revolution helped create the economic and social foundations on which present-day societies are based, such as diversified food production and storage techniques, surpluses, sedentism, labor specialization, social complexity, and ultimately state institutions. Along with these changes, it is generally recognized that the switch to agriculture resulted in, at least during initial phases, more intense labor, a less diversified diet, increased morbidity, decreased life expectancy, precarious household-based production systems, and increased intra- and inter-group conflict (Cohen, 2008; Hershkovitz and Gopher, 2008; Wittwer-Backofen and Tomo, 2008), although a number of recent studies present evidence to the contrary (Auerbach, 2011; Marchi et al., 2011; Temple, 2011). Despite these potential disadvantages, the Neolithic Revolution is traditionally perceived as the adaptive transformation that allowed human groups to move away from a reliance on predation and gathering to fulfill their subsistence needs. Little effort, though, has been made to quantitatively evaluate to what extent early production economies were sensitive to environmental constraints, if particular 
adaptations could be integrated into a broad range of environmental conditions, and whether specific cultural traditions differed ecologically. Here, we investigate whether the differences between the adaptations and geographic distributions of three major Early Neolithic archaeological cultures associated with the expansion of farming economies across the majority of the European continent are related to the exploitation of different ecological niches. First, we aim to quantify the environmental variables that define each reconstructed eco-cultural niche and identify those that were most influential for each. Second, if differences are identified between eco-cultural niche predictions, we intend to determine if they are significant. Such a focus should allow us to establish if distinct Early Neolithic cultural trajectories occurred within specific environmental settings, or if they were largely divorced from ecological factors.

We address these issues by reconstructing and comparing the eco-cultural niches (ECNs) occupied by Early Neolithic cultures in Europe: the Impressed Ware, Cardial, and Linearbandkeramik archaeological cultures. ECN modeling methods combine archaeological, chronological, geographic, and paleoclimatic datasets via biocomputational architectures, derived from biodiversity studies (see Peterson et al., 2011 for a detailed discussion of these architectures and methods), to reconstruct ecological niches occupied by prehistoric human populations. An ECN represents the array of environmental conditions within which an archaeologically recognizable human adaptive system can persist without needing to substantially shift its geographic range (Banks et al., 2008a). This methodological approach employs the Grinnellian concept of ecological niche, for which niche is defined as the subset of unlinked, nonconsumable, abiotic factors that define the environmental space occupied by a given species (or population) and serve as the basis for understanding its geographic distribution (Peterson et al., 2011). In such a framework, the combination of paleoclimatic and geographic variables that we employ can be used to effectively approximate a past ecological niche. 
The human populations being examined are represented by archaeologically-defined cultures. While archaeological cultures are modern constructs and debate exists as to what degree they reflect actual past cultural entities, our assumption is that an archaeological culture represents a population whose cohesion was based on a body of shared and transmitted knowledge that is reflected by an archaeologically recognizable suite of material culture traits (e.g., specific methods of pottery production and broad classes of decoration styles, subsistence methods, house forms, etc.). It is also important to keep in mind that a cohesive population's system of behaviors operated within an environmental context. Our focus is on relatively broadly defined archaeological cultures rather than minor and more regional subdivisions that might be defined on the basis of interrelated material culture diversity within them.

This study examines the ecological contexts of Neolithic archaeological cultures at a particular moment in which these different production economy adaptations had spread across much of the European continent and were in relative equilibrium with the environments they occupied. Therefore, our focus is not on eco-cultural niche dynamics through time (e.g., Banks et al., 2013), nor on the processes potentially involved in the colonization of new territories by an invasive population (e.g., Gallien et al., 2010; Gallien et al., 2012). Rather, once they had expanded and were in relative equilibrium, we aim to understand whether these farming adaptations were ecologically distinct from one another or if they exhibited some degree of overlap with respect to the environmental conditions they occupied. Such patterns have important implications for understanding the processes of cultural change that took place during the Early Neolithic.

Following an initial settlement in southeastern Europe, the transition to production economies across Central and Western Europe as well as northern Mediterranean regions is recognized by the spread of three cultural packages defined by different ceramic traditions and distinct suites of subsistence and settlement systems (Dolukhanov et al., 2005; Burger and Thomas, 2011). The 
Linearbandkeramik (LBK), thought to have originated out of the Starčevo-Kőrős cultural complex, dispersed through Central Europe and into northwestern Europe along the Danube corridor from ca. 7700-7000 cal BP (Price et al., 2001; Davison et al., 2006). This cultural tradition is characterized by pottery forms decorated with series of parallel, incised lines organized in bands that either meandered or took the form of spirals or chevrons. The Impressed Ware culture and, later, the Cardial Ware culture that emerged out of it, diffused west along the Mediterranean coast with the help of seafaring technology between ca. 8000-7200 cal BP (Zilhão, 2001). The Impressed Ware tradition is recognized by vessel forms decorated with casually made impressions often produced with spatulas or shells. One also finds grooved impressions associated with incisions organized in geometric motifs. The Cardial Ware tradition is also characterized by ceramics decorated with impressed designs, but the impressions were typically created by imprinting the clay surface with a Cardium edulis marine shell, although fingernail and finger impressions are occasionally present. These decorative motifs are contained in delimited bands arranged in chevron or triangular motifs, and undecorated surfaces are polished. When radiocarbon ages obtained from diagnostic materials (as opposed to bulk charcoal samples) from Impressed Ware and Cardial archaeological contexts are examined (e.g., Coppa Nevigata, Arene Candide; see Zilhão, 2001), one notes that more easterly Mediterranean occurrences of these cultures are contemporaneous with early LBK occupations in Central Europe (Stäuble, 1995). Genetic evidence, as well as modeling work, indicate that the expansions of these roughly contemporaneous cultural traditions are associated with a demic diffusion (Chikhi et al., 2002; Fort, 2012; Pinhasi and von Cramon-Taubadel, 2009; Skoglund et al., 2012), although autochthonous hunter-gatherers likely played significant roles in either facilitating or delaying the dispersal of these farming economies (Galeta et al., 2011; Isern et al., 2012). Populations associated with the LBK and Impressed Ware/Cardial archaeological cultures appear 
to have come into contact only in limited areas of Western Europe (Constantin and Vachard, 2004; Bocquet-Appel et al., 2009).

Behind the issues outlined earlier lies the question of whether the cultural processes that occurred during the evolution of these different Neolithic cultures took place within broad, but distinct, environments or if they were driven primarily by historical contingencies in which ecology played little or no role. With respect to the former, one would expect little to no interpredictivity between the ecological niches associated with different cultural entities. For example, for the scenario in which different, neighboring archaeological cultures are characterized by distinct farming adaptations associated with well-constrained suites of ecological conditions, one would expect the particular culture-environment relationships that exist to be such that these different adaptive packages have few or no ecological similarities between them. Furthermore, given this strong correspondence between type of adaptation and ecology, one would expect each archaeological culture's predicted ecological niche to correspond closely to its actual geographic distribution. Alternatively, if reconstructed ecological niches for two cultures overlap broadly, then no relationship, or at least a very weak one, likely exists between a specific cultural adaptation and ecological parameters. In such a situation, these cultures' differing geographic distributions are likely more constrained by cultural factors and historical contingencies. Previous eco-cultural niche modeling work has shown that both scenarios can be recognized among Paleolithic hunter-gatherer populations (Banks et al., 2009), and although hunter-gatherers differ from farmers with respect to how their settlement systems and social networks are structured, it is our assumption that the expected relationships outlined above between adaptation, ecology, and geographic distribution are equally applicable to lowlevel production farming economies. Hence, we apply eco-cultural niche modeling methods to 
the European Early Neolithic in order to quantitatively assess the degree to which these farming economies were constrained by environmental constraints.

\section{Materials and methods}

To estimate eco-cultural niches for the Impressed Ware, Cardial, and Linearbandkeramik Neolithic cultures, we used genetic algorithm (Genetic Algorithm for Rule-Set Prediction: GARP; Stockwell and Peters, 1999) and maximum entropy (Maxent; Phillips et al., 2006) techniques. GARP and Maxent have been applied to a diverse set of topics including reconstructing species' distributions (Pearson et al., 2007; Barve et al., 2011), estimating effects of climate change on species' distributions (Araújo and Rahbek, 2006; Banks et al., 2008b), and forecasting the geographic potential of species invasions (Peterson, 2003; Medley, 2010). For data inputs, GARP and Maxent require the geographic coordinates where the target population has been observed, and raster GIS data layers summarizing environmental dimensions potentially relevant to shaping the geographic distribution of that population.

\section{Occurrence Data}

Occurrence data were obtained from the published literature and consist of the geographic coordinates of archaeological sites containing material culture remains associated with the Impressed Ware, Cardial, or Linearbandkeramik cultures (Table S1). We included in this dataset only those archaeological sites with material remains that had been recovered from intact stratigraphic contexts and for which clear chrono-cultural identification is possible. Sites for which cultural materials only occur as surface scatters were excluded. We restricted our occurrence data for the Impressed Ware culture to sites documented in Italy since this pottery style represents a type that emerged in the region and that is substantially different from ceramic 
technologies recognized in the Balkans (Mazurié de Keroualin, 2003:100). Impressed Ware pottery on the eastern coast of the Adriatic, as well as on the Mediterranean coast west of Italy, represents regional variants that post-date the initial Impressed Ware of the Italian Peninsula (Mazurié de Keroualin, 2003:102, 112). Restricting our Impressed Ware occurrence data to sites in the Italian Peninsula provides a sample sufficient to produce robust niche predictions.

\section{Environmental Data}

The raster GIS datasets used in this study summarize landscape attributes (assumed to have remained constant) and a high-resolution paleoclimatic simulation for the mid-Holocene (6,000 cal yr BP). Landscape variables included slope, aspect, elevation, and topographic index (a measure of tendency to pool water). Elevation was obtained from the ETOPO1 dataset (Amante and Eakins, 2009), whereas the remaining landscape values were calculated from the ETOPO2 dataset (ETOPO2v2). It would be ideal to include data layers pertaining to soil type or soil characteristics. Such data would be extremely pertinent for studies at restricted geographic scales (i.e., regional or micro-regional). Compiling regional records of soil type data into raster data layers for the entire European continent, however, represents a daunting and time consuming task, and it would be difficult to ensure that data would be geographically consistent at such a large scale. It is for these reasons that soil type data were not included as a landscape variable. Furthermore, these heterogeneous data would be less likely to influence niche predictions significantly at our scale of analysis.

The high-resolution paleoclimatic simulation for the mid-Holocene (6K; Sepulchre et al., 2008) was derived from the LMDZ4 three-dimensional Atmospheric General Circulation Model (Li and Conil, 2003). The LMDZ4 model was forced by 6K values for sea surface temperatures, vegetation albedo, and surface roughness length in order to create the $6 \mathrm{~K}$ paleoclimatic 
simulation and derive values for mean annual temperature, warmest month temperature, coldest month temperature, and mean annual precipitation. The simulation has a horizontal resolution between 70-90 km over Europe, which is sufficient for examining ECN variability at a continental scale.

\section{Eco-Cultural Niche Modeling}

In GARP, occurrence data (i.e., presence-only data) are resampled randomly by the algorithm to create training and test data sets. An iterative process of rule generation and improvement then follows, in which a method is chosen randomly from a set of inferential tools-Atomic, Range, Negated Range, and Logistic Regression — and applied to the training data to develop specific rules (Stockwell and Peters, 1999). These rules evolve to maximize predictivity by several means (e.g., crossover, mutation) via a process that evaluates predictive accuracy based on an independent subsample of presence data and a set of points sampled randomly from regions where the species has not been detected. The final rule-set defines the distribution of the target population in environmental dimensions (i.e., the ecological niche: Peterson et al., 2011), which is projected onto the landscape to estimate a potential geographic distribution. For each GARP model, we performed 1000 replicate runs with a convergence limit of 0.01 , using $50 \%$ of the occurrence points for model training. We used the best subsets protocol (Anderson et al., 2003), with a hard omission threshold of $10 \%$ and a commission threshold of 50\%, and summed the resulting 10 grids to create a consensus estimate of the geographic range of the ecological niche associated with the archaeological occurrence data.

The maximum entropy (Maxent) modeling architecture uses the distribution of known occurrences to estimate a species' ecological niche by fitting a probability distribution of maximum entropy (i.e., that which is closest to uniform) to the set of pixels across the study 
region (Phillips et al., 2006). This estimated probability distribution is constrained by environmental characteristics associated with the known occurrence localities, while at the same time it aims to avoid making assumptions not supported by the background data. To produce ecocultural niche reconstructions, we used the following parameters for Maxent version 3.3.1:

random test percentage $=50$, maximum iterations $=500$, background points $=10^{4}$, and convergence limit $=10^{-5}$. This configuration approximates that used to produce the GARP predictions, in that half of available occurrence data are set aside for evaluating and refining model rule-sets.

When reconstructing ecological niches, it is important to consider the geographic areas that would have been accessible to the species or population in question via dispersal, and that have been sampled such that occurrences could have been detected (Barve et al., 2011; Peterson, 2011); this area is termed "M" in the BAM framework (Soberón and Peterson, 2005). It is important to incorporate $M$ into model training because it represents the geographic area in which presences may exist and within which absences are meaningful in ecological terms. Using overly broad designations of $M$ can significantly influence predicted geographic distributions (Barve et al., 2011). As a result, we did not use the entire geographic coverage of our environmental variables in calibrating eco-cultural niche models. Instead, our $M$ definitions incorporated into model training relatively broad regions (Fig. S1), beyond the known archaeological distributions, that potentially could have been occupied. In this way we avoided the possibility of erroneously restricting the potential limits of an archaeological culture's predicted niche.

\section{Eco-Cultural Niche Characterization}

Recent years have seen a proliferation of techniques for reconstructing ecological niches and predicting species' distributions, and debate has focused on how best to evaluate resulting models 
statistically (Araújo and Guisan, 2006; Peterson et al., 2008; Warren et al., 2008). We use a variety of methods to evaluate and compare the outputs from the two employed modeling algorithms. New methods and statistical tests (Warren et al., 2008) for quantitatively evaluating overlap between ecological niche models are available in ENMTools (enmtools.blogspot.com; Warren et al., 2010). ENMTools allows one to generate ecological niche models (ENMs) with Maxent, calculate similarity measures, and develop randomization-based comparisons of niche predictions.

To characterize each ECN, we used R to perform Principal Component Analyses (Fig. S2, S3), as well as descriptive statistics of environmental variables (Fig. S4-S7). To examine patterns of niche similarity, we employed ENMTools' niche breadth measure (inverse concentration; Table S2), overlap measures $I$ and $D$, and background similarity tests. Niche breadth is a measure of the range of abiotic conditions within which a species can maintain populations (Carnes and Slade, 1982; Levins, 1968; Soberón, 2007). Overlap measures $I$ and $D$ compare two ECNs and measure the similarity between them (Warren et al., 2008). The background similarity test evaluates whether the observed degree of similarity between two ECNs is greater than would be expected by chance. This comparison is accomplished by generating a null distribution for ECN model difference expected between one region and another based on occurrence points drawn at random from within a relevant geographic area (Warren et al., 2010), which corresponds to the $M$ s defined for this study (described above). If the calculated overlap value is significantly greater than the distribution of overlaps from the pseudo-replicates, the null-hypothesis of niche identity cannot be rejected and the two niches can be considered inter-predictive. If niche overlap is significantly less than the pseudo-replicate overlaps distribution, the null hypothesis of no difference can be rejected, meaning that the two niches are more different from one another than would be expected by chance. 


\section{Results}

Niche predictions produced with GARP and Maxent are presented in Figure 1. Both architectures provide comparable outputs. The predicted geographic ranges for the Impressed Ware and Cardial ECNs are virtually identical and cover portions of the Near East, the majority of the Anatolian, Balkan, Italian, and Iberian Peninsulas, as well as the Atlas Mountains and limited areas of Tripolitania and Cyrenaica in Northern Africa (Fig. 1A, B, D, E). Measures of niche overlap (Table 1) confirm this visual similarity. A background similarity test shows the Impressed Ware and Cardial ECNs to be interpredictive (Fig. 2A, B). These archaeological cultures can be considered as ensuant cultural phases with similar settlement and subsistence strategies, despite varying degrees of internal variability. What one is witnessing here is the dispersal of a specific adaptation within a distinct ecological niche through time rather than two cultures whose distributions differed due to environmental factors. For this reason, these cultures' respective archaeological sites were combined into a single occurrence dataset to produce an ECN prediction for this Mediterranean adaptation (Fig. 1C, F). This combined Impressed Ware/Cardial ECN (ICECN) closely resembles those of each individual phase. It occupies a latitudinal band with mean annual temperatures between $8-16.5^{\circ} \mathrm{C}$ and mean annual precipitation ranging between 360-1100 mm/year (Fig. 3, S5, S7).

The ECN for the Linearbandkeramik (LECN) covers much of the Danube River Valley, the Po Valley, the northern European Plain, and most of the British Isles (Fig. 1C, F). It occupies a range of mean annual temperatures between $3.0-8.5^{\circ} \mathrm{C}$ and mean annual precipitation ranging between ca. $700-1800 \mathrm{~mm} /$ year (Fig. 3, S5, S7).

Evaluation of the degree of overlap (Table 1) between the predictions indicates that the ICECN and LECN represent two different and essentially exclusive ecological niches. 
Background similarity evaluations demonstrate that these ECN predictions are significantly different (Fig. 2C, D). Principal Component Analyses show that temperature and precipitation are the principal parameters defining these environmental envelopes (Fig. S2, S3). With respect to the ICECN prediction, mean annual precipitation is negatively correlated with temperature variables. The inverse is true for the LECN. Topographic variables (elevation, slope, and drainage index) play an important, albeit secondary, role in the definition of the two niches (ICECN and LECN). LBK sites are generally located in unbroken landscapes below $500 \mathrm{~m}$, whereas sites belonging to the combined Impressed Ware/Cardial group reveal a distribution that includes a broader range of elevations (Fig. S5, S7).

\section{Discussion and conclusions}

As stated above, instances in which the geographic footprint of a cultural entity reflects adaptation to specific environmental conditions would be indicated by a close correspondence between an ECN prediction and the distribution of the archaeological sites used to reconstruct it. One also should observe little or no overlap between the ECNs of neighboring cultural traditions in instances where each culture was adapted to a specific suite of environmental conditions and is characterized by a strong culture-environment relationship. Inversely, if the distribution of an archaeological culture reflected more the outcome of historical processes and had little or no relation to environmental factors, one would expect the distribution of known sites to occupy a minor proportion of the predicted potential niche. In such a situation, one would also expect ECNs for different, neighboring cultures to overlap broadly.

Our results indicate that the ICECN and LECN predictions match, to a relatively large degree, the distribution of their respective sites. Therefore, early European Neolithic settlement represented a dynamic process of range expansion up to the near complete occupation of each 
archaeological culture's potential niche. Furthermore, the two niche predictions overlap minimally (Fig. 1C, F). As detailed above, these results can be interpreted to indicate that environmental factors had an influential role in the distribution of these Neolithic cultures and their relationship to one another. Thus, for the Early Neolithic, we see cultural processes and the appearance of regional variants, both in terms of ceramic traditions and agricultural adaptations, occurring within relatively broad but distinct ecological niches. The reconstructed ECNs demonstrate that the technological innovations and social practices of the LBK and Impressed Ware/Cardial cultures were tailored to specific and mutually exclusive ecological niches. One might argue that such a finding is not entirely unexpected if one assumes that these archaeological cultures were associated with different environments from the onset. What is important and informative, however, is the absence of overlap between their respective ecocultural niche predictions. It is this lack of overlap that signals the presence of a strong cultureenvironment interaction and thus can used to infer the important role of environmental factors on the cultural processes associated with the expansion of these particular Neolithic adaptations. The next logical question is whether this close correspondence between cultural adaptation and environment, along with marked ecological differentiation between neighboring archaeological cultures, are common among food producing adaptations in other regions and time periods.

One must keep in mind that with the Neolithic Transition in Europe, one is witnessing the replacement of hunter-gatherer adaptations with those of food-production, and this transition is characterized by the introduction of both domesticated plants and animals. It is reasonable to expect that these new practices would be conditioned by the different ecological settings into which the LBK and Impressed Ware/Cardial cultures expanded. Our results indicate that these early agricultural technologies were conditioned by environmental parameters, thus one should expect to see the use of different suites of cultigens between these two archaeological cultures. 
The dominant use of einkorn (both 1-grained and 2-grained varieties), a relatively low-yield cereal, by LBK groups exemplifies this expectation. Einkorn was well-suited to the relatively high precipitation characteristic of northern Europe during the Atlantic period because it remains standing after periods of high rainfall (Kreuz, 2007). LBK populations also cultivated freethreshing hexaploid wheat, as well as emmer and striate emmeroid wheats. The selection of cereals in the Mediterranean settings of the Impressed Ware/Cardial cultures differs from what is observed in northern Europe. For example, emmer and 1-grained einkorn wheat, along with freethreshing tetraploids are common in western Mediterranean regions. Additionally, pulse crops were more diverse in Mediterranean regions since many (e.g., lentils, chickpeas) were not wellsuited to northern latitudes and were abandoned during settlement of those regions (Bakels, 2012). This Mediterranean diversity fits with the more varied landscapes and environments of the region (Zapata et al., 2004) and is reflected by the ICECN's broader niche breadth (Table S2).

This is not to say, however, that historical contingencies played no role in the European Neolithic transition. Firstly, one notes that the reconstructed potential niches for the Impressed Ware and Cardial cultures, as well as the Impressed Ware/Cardial grouping, covers regions of Anatolia, the Near East, and northern Africa that were not occupied by these populations. Thus, these groups did not occupy their entire potential niche, indicating that cultural processes did influence their geographic distributions to some degree. The relatively rapid and coastal-oriented spread, and settlement of island regions, of the Impressed Ware/Cardial tradition across the Mediterranean was made possible by the use of sea faring technology (Zilhão, 2001). The creation of a maritime-based communication network was a key binding element of this cultural adaptation and likely explains the absence of settlements in inland regions of the Iberian Peninsula and northwestern Africa contrary to its predicted ECN. One also notes that the LBK culture is absent in some regions where its ECN is predicted present. This culture spread across 
Central and Northern Europe via major river valleys and did not possess maritime technologies, thereby preventing the diffusion of this cultural package into the British Isles, a process that would only take place during later phases of the Neolithic (Zvelebil and Rowley-Conwy, 1986; Bonsall et al., 2002; Davison et al., 2006). Cultural resistance of autochthonous hunter-gatherer populations to the adoption of agriculture (Raemaekers, 1997; Klassen, 2004), or a demographic shift in populations that practiced agriculture along the frontier zone of the Neolithic wave of advance (Hinz et al., 2012) could also have significantly stalled the spread of this adaptation into regions of Northern and Northwestern Europe. Both scenarios may have worked in concert to prevent the Linearbandkeramic adaptation from spreading into these northern areas.

Secondly, still with respect to cultural processes, both the LBK and the Impressed Ware/Cardial cultures used a reduced set of cultigens compared to the crop suite observed in earlier Neolithic contexts in Anatolia (Conolly et al., 2008), and it has been argued that these regional changes in plant assemblages cannot be explained solely with respect to ecological or climatic conditions (Colledge et al., 2005; Coward et al., 2008). An example along such lines is that while einkorn performed well in high rainfall conditions characteristic of the reconstructed LECN, it originated in hot and dry conditions of the Near East, yet it is absent in the analogous environmental conditions of the Mediterranean. This apparent absence, along with its presence in contrasting conditions of the LECN, does not lend itself to a purely adaptive explanation (Kreuz and Boenke, 2002; Kohler-Schneider, 2003; Fuller et al., 2012). Lastly, for the Linearbandkeramik, there is a decrease in cultigen diversity (Kreuz et al., 2005; Kreuz and Schäfer, 2011) as one moves from east to west within the LECN. Because this occurs within a single ecological niche, it suggests that cultural choices, and not simply environmental constraints, played a role in this reduction of crop diversity. 
This study's results lead us to conclude that environmental factors influenced the cultural processes that characterize the Neolithization of Europe. This finding does not imply, however, that these adaptations were inflexible. It also does not suggest that these cultures were unable to adapt their subsistence systems to the new territories into which they moved, nor incorporate input from autochthonous hunter-gatherer populations. Our results show, though, that any adaptive changes that occurred along the way did not result in the creation of distinct local variants that significantly fragmented the homogenous nature of these adaptive systems, each operating within one of the two main ecological zones that existed in Europe during the early and middle Holocene. Instead of representing a moment during which populations freed themselves from environmental constraints, our results indicate that early Neolithic adaptations in Europe reflect marked correspondence to ecological parameters. During the Neolithic Transition, cultures became reliant on specific suites of environmental conditions and many of the cultural processes at work in the evolution of these archaeological cultures appear to have operated within distinct and mutually exclusive ecological niches. Future research should focus on whether this pattern holds true for the other instances of Neolithization across the globe.

Acknowledgments: This project was funded by the European Research Council (FP7/20072013, grant no. 249587), a doctoral dissertation grant to N. Antunes from the University of Bordeaux 1, and post-doctoral funding to S. Rigaud from the Fyssen Foundation. We thank the two anonymous reviewers whose comments and suggestions served to improve the manuscript. 


\section{References cited}

Amante, C., Eakins, B.W., 2009. ETOPO1 1 Arc-Minute Global Relief Model: Procedures, Data Sources and Analysis. NOAA Technical Memorandum NESDIS NGDC-24.

Ammerman, A., Biagi, P. (Eds.), 2003. The Widening Harvest. The Neolithic Transition in Europe: Looking Back, Looking Forward. Archaeological Institute of America, Boston.

Anderson, R.P., Lew, D., Peterson, A.T., 2003. Evaluating predictive models of species' distributions: criteria for selecting optimal models. Ecol. Model. 162, 211-232.

Araújo, M.B., Guisan, A., 2006. Five (or so) challenges for species distribution modelling. J. Biogeogr. 33, 1677-1688.

Araújo, M.B., Rahbek, C., 2006. How does climate change affect biodiversity? Science 313, $1396-1397$.

Auerbach, B.M., 2011. Reaching Great Heights: Changes in Indigenous Stature, Body Size and Body Shape with Agricultural Intensification in North America, in: Pinhasi, R., Stock, J.T. (Eds.), Human Bioarchaeology of the Transition to Agriculture, Wiley-Blackwell, Chichester, UK, pp. 203-234. 
Bakels, C., 2012. The first farmers of the Northwest European Plain: some remarks on their crops, crop cultivation and impact on the environment. J. Archaeol. Sci., http://dx.doi.org/10.1016/j.jas.2012.08.046.

Banks, W.E., d'Errico, F., Peterson, A.T., Vanhaeren, M., Kageyama, M., Sepulchre, P., Ramstein, G., Jost, A., Lunt, D., 2008a. Human ecological niches and ranges during the LGM in Europe derived from an application of eco-cultural niche modeling. J. Archaeol. Sci. 35, $481-491$.

Banks, W.E., d'Errico, F., Peterson, A.T., Kageyama, M., Colombeau, G., 2008b. Reconstructing ecological niches and geographic distributions of caribou (Ragnifer tarandus) and red deer (Cervus elaphus) during the Last Glacial Maximum. Quat. Sci. Rev. 27, 2568-2575.

Banks, W.E., Zilhão, J., d'Errico, F., Kageyama, M., Sima, A., Ronchitelli, A., 2009. Investigating links between ecology and bifacial tool types in Western Europe during the Last Glacial Maximum. J. Archaeol. Sci. 36, 2853-2867.

Banks, W.E., d'Errico, F., Zilhão, J., 2013. Human-climate interaction during the Early Upper Paleolithic: testing the hypothesis of an adaptive shift between the Proto-Aurignacian and the Early Aurignacian. J. Hum. Evol. 64, 39-55.

Barker, G., 2006. The Agricultural Revolution in Prehistory: Why did Foragers Become Farmers? Oxford University Press, Oxford. 
Barve, N., Barve, V., Jiménez-Valverde, A., Lira-Noriega, A., Maher, S.P., Peterson, A.T., Soberón, J., Villalobos, F., 2011. The crucial role of the accessible area in ecological niche modeling and species distribution modeling. Ecol. Model. 222, 1810-1819.

Bellwood, P., 2005. First Farmers: The Origins of Agricultural Societies. Blackwell, Oxford.

Bocquet-Appel, J.-P., 2002. Paleoanthropological Traces of a Neolithic Demographic Transition. Curr. Anthropol. 43, 637-650.

Bocquet-Appel, J.-P., Bar-Yosef, O. (Eds.), 2008. The Neolithic Demographic Transition and Its Consequences. Springer, New York.

Bocquet-Appel, J.-P., Naji, S., Vander Linden, M., Kozlowski, J.K., 2009. Detection of diffusion and contact zones of early farming in Europe from the space-time distribution of 14C dates. J. Archaeol. Sci. 36, 807-820.

Bonsall, C., Macklin, M.G., Anderson, D.E., Payton, R.W., 2002. Climate Change and the Adoption of Agriculture in North-West Europe. Eur. J. Archaeol. 5, 9-23.

Bowles, S., 2011. Cultivation of cereals by the first farmers was not more productive than foraging. Proc. Natl. Acad. Sci. 108, 4760-4765. 
Burger, J., Thomas, M.G., 2011. The Palaeopopulationgenetics of Humans, Cattle, and Dairying in Neolithic Europe, in Pinhasi, R., Stock, J.T. (Eds.), Human Bioarchaeology of the Transition to Agriculture. Wiley, Oxford, pp. 371-384.

Carnes, B.A., Slade, N.A. 1982. Some comments on Niche Analysis in Canonical Space. Ecology 63, 888-893.

Chikhi, L., Nichols, R.A., Barbujani, G., Beaumont, M.A., 2002. Y genetic data support the Neolithic demic diffusion model. Proc. Natl. Acad. Sci. 99, 11009-11013.

Cohen, M.N., 2008. Implications of the NDT for World Wide Health and Mortality in Prehistory, in: Bocquet-Appel, J.-P., Bar-Yosef, O. (Eds.), The Neolithic Demographic Transition and its Consequences. Springer, New York, pp. 481-500.

Colledge, S., Conolly, J., Shennan, S., 2005. The evolution of Neolithic farming from SW Asian origins to NW European limits. Eur. J. Archaeol. 8, 137-156.

Conolly, J., Colledge, S., Shennan, S., 2008. Founder effect, drift, and adaptive change in domestic crop use in early Neolithic Europe. J. Archaeol. Sci. 35, 2797-2804.

Constantin, C., Vachard, D., 2004. Anneaux d'origine méridionale dans le Rubané récent du Bassin parisien. Bull. Soc. Préhist. Fr. 101, 75-83. 
Coward, F., Shennan, S., Colledge, S., Conolly, J., Collard, M., 2008. The spread of Neolithic plant economies from the Near East to northwest Europe: a phylogenetic analysis. J. Archaeol. Sci. 35, 42-56.

Davison, K., Dolukhanov, P.M., Sarson, G.R., Shukurov, A., 2006. The role of waterways in the spread of the Neolithic. J. Archaeol. Sci. 33, 641-652.

Dolukhanov, P., Shukurov, A., Gronenborn, D., Sokoloff, D., Timofeev, V., Zaitseva, G., 2005. The chronology of Neolithic dispersal in Central and Eastern Europe. J. Archaeol. Sci. 32, $1441-1458$.

Fort, J., 2012. Synthesis between demic and cultural diffusion in the Neolithic transition in Europe. Proc. Natl. Acad. Sci. 109, 18669-18673.

Fuller, D.Q., Willcox, G., Allaby, R.G., 2012. Early Agricultural Pathways: moving outside the 'core area' hypothesis in Southwest Asia. J. Exp. Bot. 63, 617-633.

Galeta, P., Sladek, V., Sosna, D., Bruzek, J., 2011. Modeling Neolithic Dispersal in Central Europe: Demographic Implications. Am. J. Phys. Anthropol. 146, 104-115.

Gallien, L., Münkemüller, T., Albert, C.H., Boulangeat I., Thuiller, W., 2010. Predicting potential distributions of invasive species: where to go from here? Divers. Distrib. 16, 331342. 
Gallien, L., Douzet, R., Pratte, S., Zimmermann, N.E., Thuiller, W., 2012. Invasive species distribution models - how violating the equilibrium assumption can create new insights. Glob. Ecol. Biogeogr. 21, 1126-1136.

Gronenborn, D., 2009. Climate fluctuations and trajectories to complexity in the Neolithic: towards a theory. Doc. Praehist. 36, 97-110.

Hershkovitz, I., Gopher, A., 2008. Demographic, Biological and Cultural Aspects of the Neolithic Revolution: A View from the Southern Levant, in: Bocquet-Appel, J.-P., Bar-Yosef, O. (Eds.), The Neolithic Demographic Transition and its Consequences. Springer, New York, pp. $441-479$.

Hinz, M., Feeser, I., Sjögren, K.-G., Müller, J., 2012. Demography and the intensity of cultural activities: an evaluation of Funnel Beaker Societies (4200-2800 cal BC). J. Archaeol. Sci. 39, $3331-3340$.

Isern, N., Fort, J., Vander Linden, M., 2012. Space Competition and Time Delays in Human Range Expansions. Application to the Neolithic Transition. PLoS ONE 7(12), e51106.

Klassen L., 2004. Jade und Kupfer. Untersuchungen zum Neolithisierungsprozess im westlichen Ostseeraum unter besonderer Berücksichtigung der Kulturentwicklung Europas 5500 - 3500 BC. Jysk Arkaeol. Selskabs Skr. 47 (Højbjerg 2004). 
Kohler-Schneider, M., 2003. Contents of a storage pit from late Bronze Age Stillfried, Austria: another record of the "new" glume wheat. Veg. Hist. Archaeobot. 12, 105-111.

Kreuz, A., 2007. Archaeobotanical perspectives on the beginning of agriculture north of the Alps, in: Colledge, S., Conolly, J. (Eds.), Archaeobotanical perspectives on the origin and spread of agriculture in south west Asia and Europe. Left Coast Press, Walnut Creek, pp. 259-294.

Kreuz, A., Boenke, N., 2002. The presence of two-grained einkorn at the time of the Bandkeramik culture. Veg. Hist. Archaeobot. 11, 233-240.

Kreuz, A., Marinova, E., Schäfer, E., Wiethold, J., 2005. A comparison of early Neolithic crop and weed assemblages from the Linearbandkeramik and the Bulgarian Neolithic cultures: differences and similarities. Veg. Hist. Archaeobot. 14, 237-258.

Kreuz, A., Schäfer, E., 2011. Weed finds as indicators for the cultivation regime of the early Neolithic Bandkeramik culture? Veg. Hist. Archaeobot. 20, 333-348.

Levins, R., 1968. Evolution in Changing Environments. Princeton University Press (Monographs in Population Biology, vol. 2), Princeton.

Li, Z.X., Conil, S., 2003. Transient response of an atmospheric GCM to North Atlantic SST anomalies. J. Clim. 16, 3993-3998. 
Marchi, D., Sparacello, V., Shaw, C., 2011. Mobility and Lower Limb Robusticity of a Pastoralist Neolithic Population from North-Western Italy, in: Pinhasi, R., Stock, J.T. (Eds.), Human Bioarchaeology of the Transition to Agriculture, John Wiley and Sons, Chichester, UK, pp. 317-346.

Mazurié de Keroualin, K., 2003. Genèse et diffusion de l'agriculture en Europe: Agriculteurs, Chasseurs, Pasteurs. Editions Errance, Paris.

Medley, K.A., 2010. Niche shifts during the global invasion of the Asian tiger mosquito, Aedes albopictus Skuse (Culicidae), revealed by reciprocal distribution models. Glob. Ecol. Biogeogr. 19, 122-133.

Mithen, S., 2007. Did farming arise from a misapplication of social intelligence? Philos. Trans. R. Soc. Lond. B 362, 705-718.

Pearson, R.G., Raxworthy, C. J., Nakamura, M., Peterson, A.T., 2007. Predicting species’ distributions from small numbers of occurrence records: a test case using cryptic geckos in Madagascar. J. Biogeogr. 34, 102-117.

Peterson, A.T., 2003. Predicting the geography of species' invasions via ecological niche modeling. Q. Rev. Biol. 78, 419-433.

Peterson, A.T., Papeş, M., Soberón, J., 2008. Rethinking receiver operating characteristic analysis applications in ecological niche modeling. Ecol. Model. 213, 63-72. 
Peterson, A.T., 2011. Ecological niche conservatism: a time-structured review of evidence. J. Biogeogr. 38, 817-827.

Peterson, A.T., Soberón, J., Pearson, R.G., Anderson, R.P., Martínez-Meyer, E., Nakamura, M., Araújo, M.B., 2011. Ecological Niches and Geographic Distributions. Princeton University Press (Monographs in Population Biology, vol. 49), Princeton.

Phillips, S.J., Anderson, R.P., Schapire, R.E., 2006. Maximum entropy modeling of species geographic distributions. Ecol. Model. 190, 231-259.

Pinhasi, R., von Cramon-Taubadel, N., 2009. Craniometric Data Supports Demic Diffusion Model for the Spread of Agriculture into Europe. PloS ONE 4, e6747.

Price, T.D., Bentley, R.A., Lüning, J., Gronenborn, D., Wahl, J., 2001. Prehistoric human migration in the Linearbandkeramik of Central Europe. Antiq. 75, 593-603.

Raemaekers, D., 1997. The History of the Ertebølle Parallel in Dutch Neolithic Studies and the Spell of the Point-Based Pottery. Archaeol. Dialogues 4, 220-234.

Richerson, P.J., Boyd, R., Bettinger, R.L., 2001. Was Agriculture Impossible during the Pleistocene but Mandatory during the Holocene? A Climate Change Hypothesis. Am. Antiq. $66,387-411$. 
Rindos, D., 1984. The Origins of Agriculture: An Evolutionary Perspective. Academic Press, Orlando.

Rowley-Conwy, P., Layton, R., 2011. Foraging and farming as niche construction: stable and unstable adaptations. Philos. Trans. R. Soc. Lond. B 366, 849-862.

Sepulchre, P., Schuster, M., Ramstein, G., Krinner, G., Girard, J.-F., Vignaud, P., Brunet, M., 2008. Evolution of Lake Chad Basin hydrology during the mid-Holocene: A preliminary approach from lake to climate modelling. Glob. Planet. Chang. 61, 41-48.

Skoglund, P., Malmström, H., Raghavan, M., Storå, J., Hall, P., Willerslev, E., Gilbert, M.T.P., Götherström, A., Jakobsson, M., 2012. Origins and Genetic Legacy of Neolithic Farmers and Hunter-Gatherers in Europe. Science 336:466-469.

Soberón, J., 2007. Grinnellian and Eltonian niches and geographic distributions of species. Ecol. Lett. 10, 1115-1123.

Soberón, J., Peterson, A.T., 2005. Interpretation of models of fundamental ecological niches and species' distributional areas. Biodivers. Informa. 2, 1-10.

Stäuble, H., 1995. Radiocarbon dates of the earliest Neolithic in Central Europe. Radiocarbon 37, $227-237$. 
Stockwell, D.R.B., Peters, D.P., 1999. The GARP modelling system: problems and solutions to automated spatial prediction. International J. Geogr. Inf. Syst. 13, 143-158.

Temple, D.H., 2011. Evolution of Postcranial Morphology during the Agricultural Transition in Prehistoric Japan, in: Pinhasi, R., Stock, J.T. (Eds.), Human Bioarchaeology of the Transition to Agriculture, John Wiley and Sons, Chichester, UK, pp. 235-264.

Warren, D.L., Glor, R.E., Turelli, M., 2008. Environmental niche equivalency versus conservatism: quantitative approaches to niche evolution. Evolution 62, 2868-2883.

Warren, D.L., Glor, R.E., Turelli, M., 2010. ENMTools: a toolbox for comparative studies of environmental niche models. Ecography 33, 607-611.

Weninger, B., Alram-Stern, E., Bauer, E., Clare, L.,Danzeglocke, U., Jöris, O., Kubatzki, C., Rollefson, G., Todorova, H., van Andel, T., 2006. Climate forcing due to the 8200 cal yr BP event observed at Early Neolithic sites in the eastern Mediterranean. Quat. Res. 66, 401-420.

Wittwer-Backofen, U., Tomo, N., 2008. From Health to Civilization Stress? In Search for Traces of a Health Transition During the Early Neolithic in Europe, in: Bocquet-Appel, J.-P., BarYosef, O. (Eds.), The Neolithic Demographic Transition and its Consequences. Springer, New York, pp. 501-538.

Zapata, L., Pena-Chocarro, L., Pérez-Jorda, G., Hans-Peter, S., 2004. Early Neolithic Agriculture in the Iberian Peninsula. J. World Prehist. 18, 283-325. 
Zilhão, J., 2001. Radiocarbon evidence for maritime pioneer colonization at the origins of farming in west Mediterranean Europe. Proc. Natl. Acad. Sci. 98, 14180-14185.

Zvelebil, M., Rowley-Conwy, P., 1986. Foragers and farmers in Atlantic Europe, in: Zvelebil, M. (Ed.), Hunters in Transition: Mesolithic societies of temperate Eurasia and their transition to farming. Cambridge University Press, Cambridge, pp. 67-93.

\section{Table legend}

Table 1: Measures of overlap between eco-cultural niche (ECN) predictions.

\section{Figure legends}

Figure 1: Eco-cultural niche (ECN) predictions. GARP-produced: A) Impressed Ware Culture, B) Cardial culture, C) Impressed Ware/Cardial combination (depicted in orange) and Linearbandkeramik (depicted in green); Maxent-produced: D) Impressed Ware, E) Cardial, F) Impressed Ware/Cardial combination (depicted in orange) and Linearbandkeramik (depicted in green). Colors range from light to dark, or low to high probability of presence, respectively.

Figure 2: Histograms of background similarity replicate overlap measures issuant from comparisons between Maxent-produced niche estimations. A) Impressed Ware vs. Cardial, $I$ statistic, B) Impressed Ware vs. Cardial, $D$-statistic. For A and B, grey bars represent Cardial vs. 
Impressed Ware and black bars reflect Impressed Ware vs. Cardial; C) Impressed Ware/Cardial combination vs. Lindearbandkeramic, $I$-statistic, D) Impressed Ware/Cardial combination vs. Lindearbandkeramic, $D$-statistic. For $\mathbf{C}$ and $\mathbf{D}$, grey bars represent Impressed Ware/Cardial vs. LBK and black bars reflect LBK vs. Impressed Ware/Cardial. Dashed vertical line indicates calculated overlap values between Maxent-produced ECNs (see Table 1).

Figure 3: Maxent-produced eco-cultural niche predictions for the Impressed Ware/Cardial combination (orange) and the Linearbandkeramik (green) in relation to mean annual temperature $\left(\mathrm{MAT},{ }^{\circ} \mathrm{C}\right)$ and mean daily precipitation $(\mathrm{MDP}, \mathrm{mm})$ isotherms. 
Table 1: Measures of overlap between eco-cultural niche $(\mathrm{ECN})$ predictions.

\begin{tabular}{|l|l|l|}
\hline & I-statistic & $D$ - statistic \\
\hline GARP ECNs & & \\
\hline Cardial vs. Impressa & 0.546 & 0.373 \\
\hline Mediterranean vs. LBK & 0.000 & 0.000 \\
\hline Maxent ECNs & & \\
\hline Cardial vs. Impressa & 0.969 & 0.787 \\
\hline Mediterranean vs. LBK & 0.003 & 0.002 \\
\hline
\end{tabular}




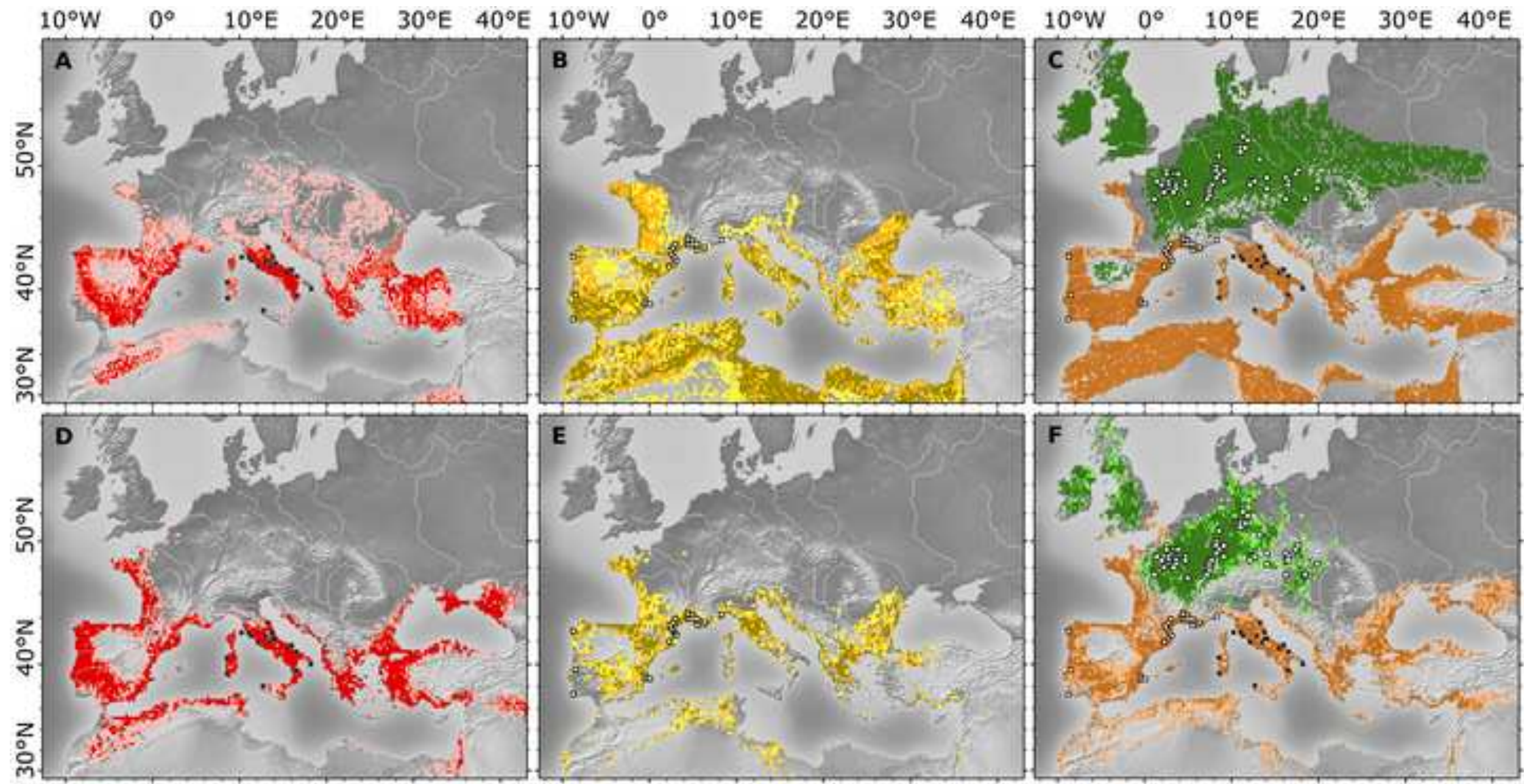



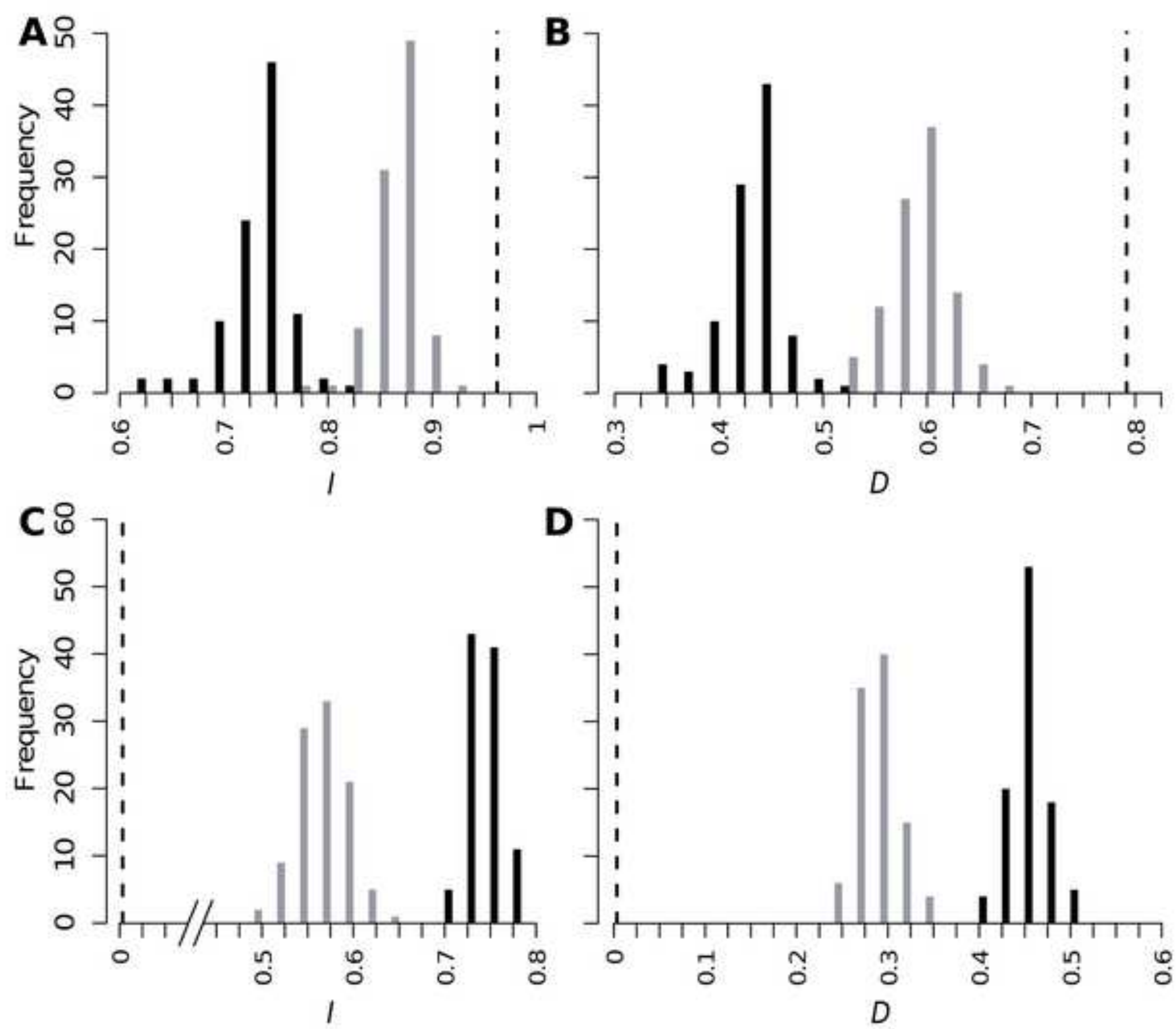
Figure 3
Click here to download high resolution image

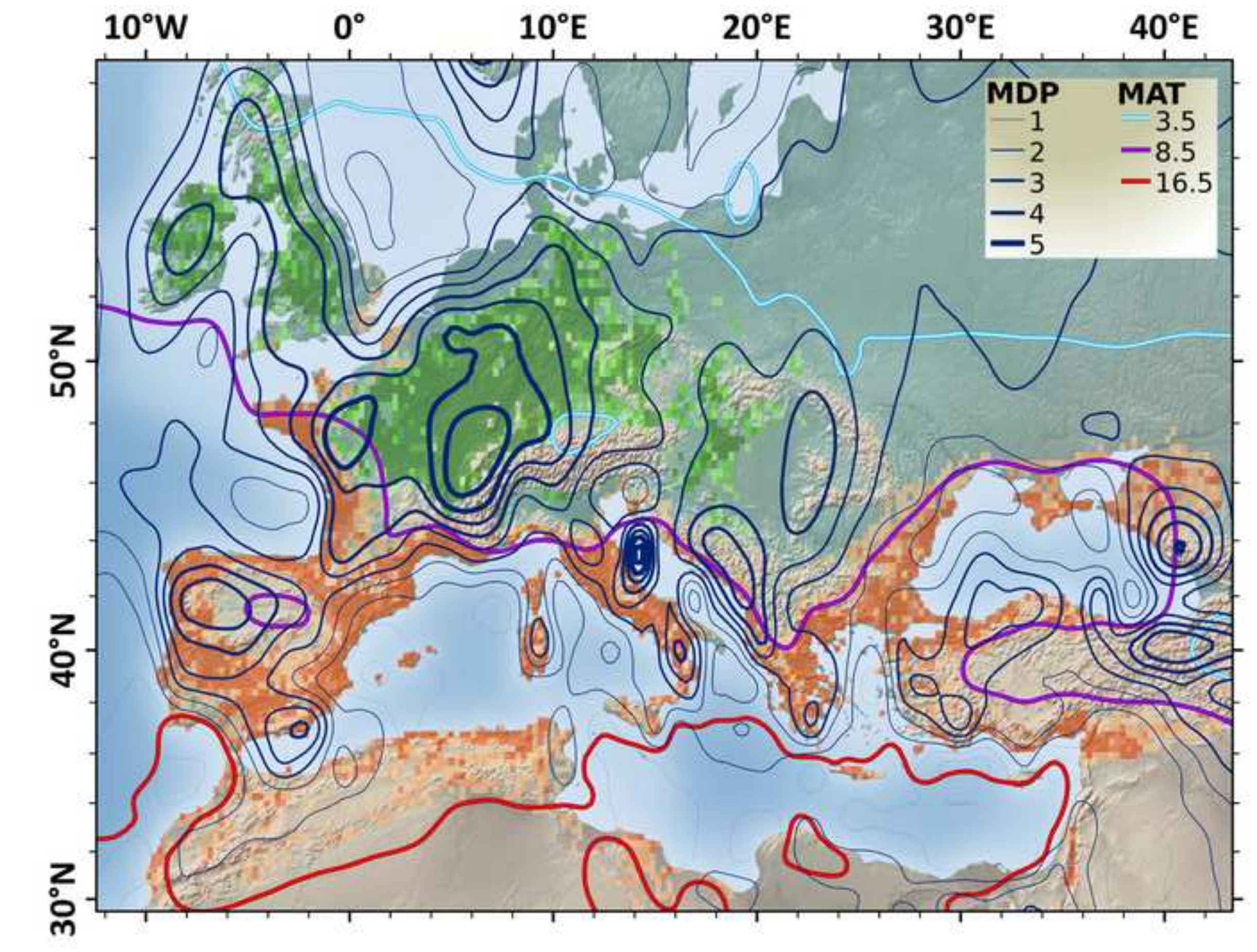


Supplementary Material

Click here to download Supplementary Material: Banks_SI_complete.pdf

upplementary Material: Banks_SI_complete.pdf

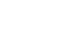

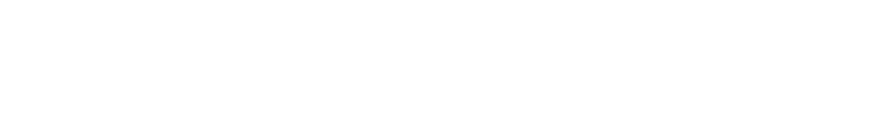

